\title{
Risks of Covid-19 Infection from Human-Non-Human Wildlife in Present Scenario
}

\section{Dr. Ishita Ganguly*}

Department of Zoology, Ex Faculty, Assistant Professor, K.L. Mehta Dayanand College for Women Faridabad and Ex PhD Scholar at Amity Institute of Forestry and Wildlife, Amity University Noida, India

*Corresponding Author: Dr. Ishita Ganguly, Department of Zoology, Ex Faculty, Assistant Professor, K.L. Mehta Dayanand College for Women Faridabad and Ex PhD Scholar at Amity Institute of Forestry and Wildlife, Amity University Noida, India.
Received: June 24, 2021

Published: June 30, 2021

(C) All rights are reserved by Dr. Ishita

Ganguly.
On the rise of Covid-19 virus globally, it is important to rise questions on human to non-human wildlife transfer of the disease in present scenario. Rhinolophid bats were considered as the most potential evolutionary source for Covid-19 virus but human-to-non-human wildlife transmission (zooanthroponotic potential) has happened on numerous events, in different nations, and including a few animal groups. In any case, almost certainly, further cases in animal life will arise since numerous Covids have an expansive host range [1]. Transmission of diseases caused mass mortality in wild populations of nonhuman primates earlier [2]. Rhesus macaques were used as biomedical tool in covid case studies at first in case of non-human wildlife and macaques were found to develop symptoms in response to infection that closely resembled infections of humans following the development of COVID-19. After recognizing the potential danger of this covid virus to nonhuman primates, the International Union for the Conservation of Nature (IUCN) [3], together with Great Apes section of the Primate Specialist Group, released a joint statement on several precautions that should be taken for researchers and caretakers while interacting with great apes in wild and laboratories. All pathogenic human coronaviruses have their origin in animals [4] but the impact of human-to-animal transmission of covid virus has not been extensively studied yet. In the rise of pandemic, it has now become critical to understand the wide range of animals (example: cats, ferrets, hamsters, non-human primates, minks, tree shrews, raccoon dogs, fruit bats, and rabbits) that are susceptible and permissive to this virus groups [5]. Ecology and evolution of human to non-human wildlife transmission of covid-19 virus needs utmost attention of researchers and scientists of different fields of animal studies to understand host-host interactions and identify high risk species. Studying host-virus interactions in susceptible species will help in determining the long-term infection status of these animals, effect on long-term immunity and persistence. If we can predict risks of viral infection in susceptible animal species at their population level, then it might save thousand animal lives from deadly outcomes of covid attack and re-emergence of the disease in future.

\section{Bibliography}

1. Vijaykrishna D., et al. "Evolutionary insights into the ecology of coronaviruses". Journal of Virology 81.8 (2007): 4012-4020.

2. Holzmann I., et al. "Impact of yellow fever outbreaks on two howler monkey species (Alouatta guariba clamitans and A. caraya) in Misiones, Argentina". American Journal of Primatology 72 (2010): 475-480.

3. IUCN SSC Wildlife Health Specialist Group and Primate Specialist Group, Section on Great Apes. Great apes, COVID-19 and the SARS CoV-2 joint statement of the IUCN SSC Wildlife Health Specialist Group and the Primate Specialist Group, Section on Great Apes. Great apes and SARS CoV 2 Communique (2020).

4. Cui J., et al. "Origin and evolution of pathogenic coronaviruses". Nature Reviews Microbiology 17 (2019): 181-192. 
5. Oude Munnink BB., et al. "Transmission of SARSCoV-2 on mink farms between humans and mink and back to humans". Science 371 (2021): 172-177.

Volume 3 Issue 7 July 2021

(C) All rights are reserved by Dr. Ishita Ganguly. 